\title{
Kinetics and mechanism of oxidation of dimethyl sulphoxide by sodium bromate-sodium bisulphite reagent in aqueous medium
}

\author{
J VIROOPAKSHAPPA and V JAGANNADHAM* \\ Department of Chemistry, Osmania University, Hyderabad 500 007, India \\ e-mail: jvandanapu@hotmail.com
}

MS received 19 November 2001; revised 16 March 2002

\begin{abstract}
Rates of oxidation of dimethyl sulphoxide (DMSO) by HOBr produced in situ from sodium bromate-sodium bisulphite reagent have been studied iodometrically in aqueous medium. The order in [DMSO] is one when [DMSO] $<0.01 \mathrm{~mol} \mathrm{dm}^{-3}$, fractional when [DMSO] is between 0.01 and $0.5 \mathrm{~mol} \mathrm{dm}^{-3}$ and zero when $(\mathrm{DMSO})>0.5 \mathrm{~mol} \mathrm{dm}^{-3}$. Different rate laws are operative under these three conditions though $\mathrm{HOBr}$ is the effective oxidizing species in all the cases. A mechanism involving an intermediate four-membered cyclic transition state between DMSO and $\mathrm{HOBr}$ (formation constant $K$ ), which decomposes in a slow step with a rate constant $(k)$ has been proposed. Thermodynamic parameters for the adduct formation step and activation parameters for the first-order decomposition of the adduct step have been evaluated in the temperature range $308-323 \mathrm{~K}$. Activation parameters have also been determined while the orders in [DMSO] are unity and zero. The reaction product has been identified as dimethyl sulphone $\left(\mathrm{DMSO}_{2}\right)$.
\end{abstract}

Keywords. Oxidation of DMSO; sodium bromate-sodium bisulphite reagent.

\section{Introduction}

Kinetic studies on the oxidation of DMSO by a number of $\mathrm{N}$-halo compounds like bromamine- $\mathrm{T}^{1}$, bromamine- $\mathrm{B}^{2}$, chloramine- $\mathrm{T}^{3}$, chloramine- $\mathrm{B}^{4}$, N-bromosuccinamide ${ }^{5}$, $\mathrm{N}$-chlorosuccinamide ${ }^{6}$, and $\mathrm{N}$-bromoacetamide ${ }^{6-8}$ have already been reported. Oxidation of DMSO in queous medium also has been reported from our laboratory in which $\mathrm{HOBr}$ was established as effective oxidizing species ${ }^{8}$. Oxidation of DMSO by sodium bromatesodium bisulphite reagent in aqueous medium has not reported in literature so far. $\mathrm{HOBr}$ was found to be easily generated in situ from $\mathrm{NaBrO}_{3}$ in the presence of appropriate reducing agent like $\mathrm{NaHSO}_{3}$ in aqueous medium ${ }^{9}$. Hence we thought it worthwhile to undertake the title investigation with focus on the elucidation of the mechanism of its reaction.

\section{Materials and methods}

All the chemicals used were of $\mathrm{AR}$ grade. $\mathrm{NaBrO}_{3}$ and $\mathrm{NaHSO}_{3}$ used in this study were BDH. DMSO (E Merck) was distilled and used. All the aqueous solutions were prepared in double-distilled water. The reaction between DMSO and sodium bromate-sodium bisulphite reagent was studied in aqueous medium. In the kinetic study, aqueous solutions

*For correspondence 
of $\mathrm{NaBrO}_{3}$ and $\mathrm{NaHSO}_{3}$ were allowed to react together for two hours to generate $\mathrm{HOBr}$ completely first (step 1), and then kinetic run started with substrate DMSO. The course of the reaction was followed by estimating the unreacted $\mathrm{HOBr}$ iodometrically at regular intervals of time. The reaction product was identified as dimethyl sulphone. To see the effect of dissolved oxygen on the rates, nitrogen gas was bubbled through the reaction mixture to expel dissolved oxygen and the reaction studied. It was found that there was no effect of oxygen on the rate. The stoichiometry was determined to be 1:1 (DMSO:HOBr) in accordance with (2) below

$$
\begin{aligned}
& 2 \mathrm{NaBrO}_{3}+2 \mathrm{NaHSO}_{3} \rightarrow 2 \mathrm{HOBr}+2 \mathrm{Na}_{2} \mathrm{SO}_{4}+\mathrm{O}_{2}, \\
& \text { (aq) } \\
& \text { (aq) } \\
& \mathrm{DMSO}+\mathrm{HOBr} \rightarrow \mathrm{DMSO}_{2}+\mathrm{HBr} .
\end{aligned}
$$

\section{Results and discussions}

Under the conditions [DMSO $\quad[\mathrm{HOBr}]$, the plots of $\log [\mathrm{HOBr}]$ versus time are linear indicating first-order dependence on $[\mathrm{HOBr}]$. From the slopes of such plots, the pseudofirst order rate constants $\left(k_{\mathrm{obs}}\right)$ have been evaluated at different initial [DMSO]. The order in [DMSO] is fractional when [DMSO] is between 0.01 and $0.5 \mathrm{~mol} \mathrm{dm}$. A fractional order in [DMSO] points to the formation of an intermediate adduct between DMSO and $\mathrm{HOBr}$ (step 3). This fact is further supported by the linearity of $1 / k_{\text {obs }}$ versus $1 /$ [DMSO] plot with finite intercepts. This adduct decomposes in a rate-determining step to yield the product $\mathrm{DMSO}_{2}$.

In this study $\mathrm{HOBr}$ has been well established to be the only effective oxidizing species ${ }^{8-10}$. This is further supported by the fact that $\mathrm{HOBr}$ in aqueous solution is a weak acid $\left(K_{\mathrm{a}}=2 \times 10^{-9}\right.$ at $\left.25^{\circ} \mathrm{C}\right){ }^{10 \mathrm{a}}$. Water is relatively a much weaker acid than $\mathrm{HOBr}$ (self ionization constant of water $=1 \times 10^{-14}$ at $25^{\circ} \mathrm{C}$ ) ${ }^{10 \mathrm{~b}}$. Hence protonation of $\mathrm{HOBr}$ (i.e. formation of $\mathrm{H}_{2} \mathrm{OBr}^{+}$) is ruled out. The rates remain unaffected by added $\mathrm{Na}_{2} \mathrm{SO}_{4}$ salt indicating that reaction may involve two dipoles, i.e. DMSO and $\mathrm{HOBr}$. Based on the product analysis, experimental observations, stoichiometry and foregoing discussions, the mechanism shown in scheme 1 is proposed for the oxidation of DMSO by sodium bromate-sodium bisulphite reagent in neutral medium at [DMSO] $>0.01 \mathrm{~mol} \mathrm{dm}^{-3}$ and $<0.5 \mathrm{~mol} \mathrm{dm}^{-3}$.

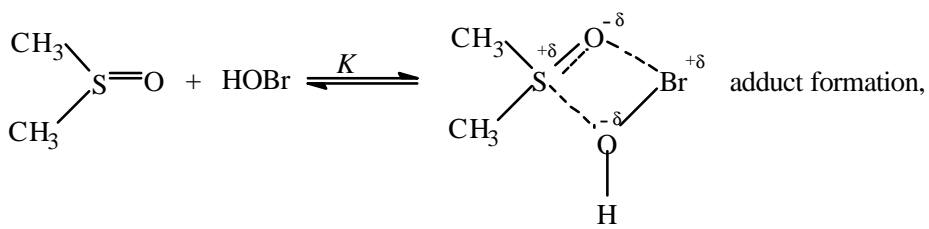

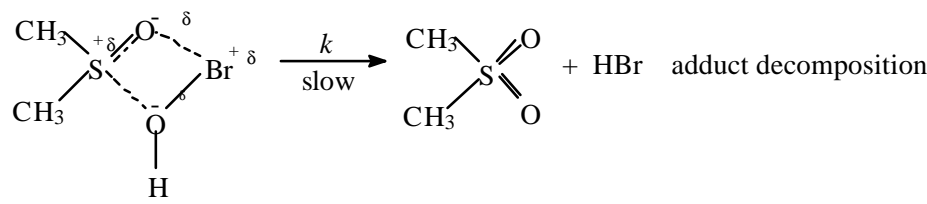

Scheme 1. 
Scheme 1 leads to the rate law,

$$
\text { rate }=\frac{k K[\mathrm{DMSO}][\mathrm{HOB} \mathrm{r}]}{1+K[\mathrm{DMSO}]},
$$

or

$$
\frac{-2 \cdot 303 \mathrm{~d} \log [\mathrm{HOBr}]}{\mathrm{d} t}=k_{\mathrm{obs}}=\frac{k K[\mathrm{DMSO}]}{1+K[\mathrm{DMSO}]}
$$

where $k_{\text {obs }}$ is the observed pseudo-first order rate constant, $k$ the first order rate constant for the decomposition of the adduct, and $K$ the formation constant of the adduct.

Table 1. Order in [DMSO] in DMSO-HOBr reaction.

$\left[\mathrm{NaBrO}_{3}\right]=1.00 \times 10^{-3} \mathrm{~mol} \mathrm{dm}^{-3} ;\left[\mathrm{NaHSO}_{3}\right]=2.00 \times 10^{-3} \mathrm{~mol} \mathrm{dm}^{-3} ;[\mathrm{DMSO}]=$

\begin{tabular}{|c|c|c|c|c|c|}
\hline$[\mathrm{DMSO}]\left(\mathrm{mol} \mathrm{dm}^{-3}\right)$ & $k_{\mathrm{obs}} \times 10^{2} \mathrm{~min}^{-1}$ & $2+\log [\mathrm{DMSO}]$ & $2+\log k_{\mathrm{obs}}$ & 1/[DMSO] & $1 / k_{\mathrm{obs}}$ \\
\hline $0 \cdot 030$ & 1.23 & 0.477 & 0.090 & $33 \cdot 3$ & $66 \cdot 8$ \\
\hline $0 \cdot 050$ & $1 \cdot 50$ & $0 \cdot 700$ & $0 \cdot 176$ & $20 \cdot 0$ & $62 \cdot 0$ \\
\hline $0 \cdot 080$ & 1.69 & 0.903 & $0 \cdot 228$ & $12 \cdot 5$ & $57 \cdot 9$ \\
\hline $0 \cdot 100$ & 1.84 & 1.00 & $0 \cdot 265$ & $10 \cdot 0$ & $49 \cdot 0$ \\
\hline $0 \cdot 200$ & 2.23 & $1 \cdot 30$ & $0 \cdot 348$ & $5 \cdot 00$ & $43 \cdot 0$ \\
\hline $0 \cdot 300$ & $2 \cdot 53$ & 1.48 & 0.403 & $3 \cdot 33$ & $41 \cdot 1$ \\
\hline $0 \cdot 400$ & $2 \cdot 76$ & 1.60 & $0 \cdot 441$ & $2 \cdot 50$ & $39 \cdot 5$ \\
\hline $0 \cdot 500$ & $3 \cdot 00$ & $1 \cdot 70$ & 0.477 & $2 \cdot 00$ & $37 \cdot 5$ \\
\hline
\end{tabular}
$0 \cdot 03-0 \cdot 5 \mathrm{~mol} \mathrm{dm}^{-3}$; temp. $=313 \mathrm{~K}$

Table 2. Effect of [DMSO] on $k_{\text {obs }}$ in DMSO-HOBr reaction when [DMSO] > $0.5 \mathrm{~mol} \mathrm{dm}^{-3}$.

$\left[\mathrm{NaBrO}_{3}\right]=1.00 \times 10^{-3} \mathrm{~mol} \mathrm{dm}^{-3} ;\left[\mathrm{NaHSO}_{3}\right]=2.00 \times 10^{-3} \mathrm{~mol} \mathrm{dm}^{-3} ;$ temp. $=313 \mathrm{~K}$

\begin{tabular}{llllll}
\hline$[\mathrm{DMSO}]\left(\mathrm{mol} \mathrm{dm}^{-3}\right)$ & 0.60 & 0.70 & 0.80 & 0.90 & 1.00 \\
\hline$k_{\mathrm{obs}} \times 10^{2}$ & 3.07 & 3.15 & 3.11 & 3.19 & 3.07 \\
\hline
\end{tabular}

Table 3. Effect of [DMSO] on $k_{\text {obs }}$ in DMSO-HOBr reaction when [DMSO] < $0.01 \mathrm{~mol} \mathrm{dm}^{-3}$.

$\left[\mathrm{NaBrO}_{3}\right]=1.00 \times 10^{-3} \mathrm{~mol} \mathrm{dm}^{-3} ;\left[\mathrm{NaHSO}_{3}\right]=2.00 \times 10^{-3} \mathrm{~mol} \mathrm{dm}^{-3} ;$ temp. $=313 \mathrm{~K}$

\begin{tabular}{lccc}
\hline$[\mathrm{DMSO}]\left(\mathrm{mol} \mathrm{dm}^{-3}\right)$ & $k_{\mathrm{obs}} \times 10^{3}\left(\mathrm{~min}^{-1}\right)$ & $3+\log [\mathrm{DMSO}]$ & $3+\log k_{\mathrm{obs}}$ \\
\hline 0.007 & 8.55 & 0.845 & 0.936 \\
0.008 & 9.54 & 0.903 & 0.982 \\
0.009 & 10.9 & 0.954 & 1.00 \\
0.010 & 11.8 & 1.00 & 1.07 \\
\hline
\end{tabular}




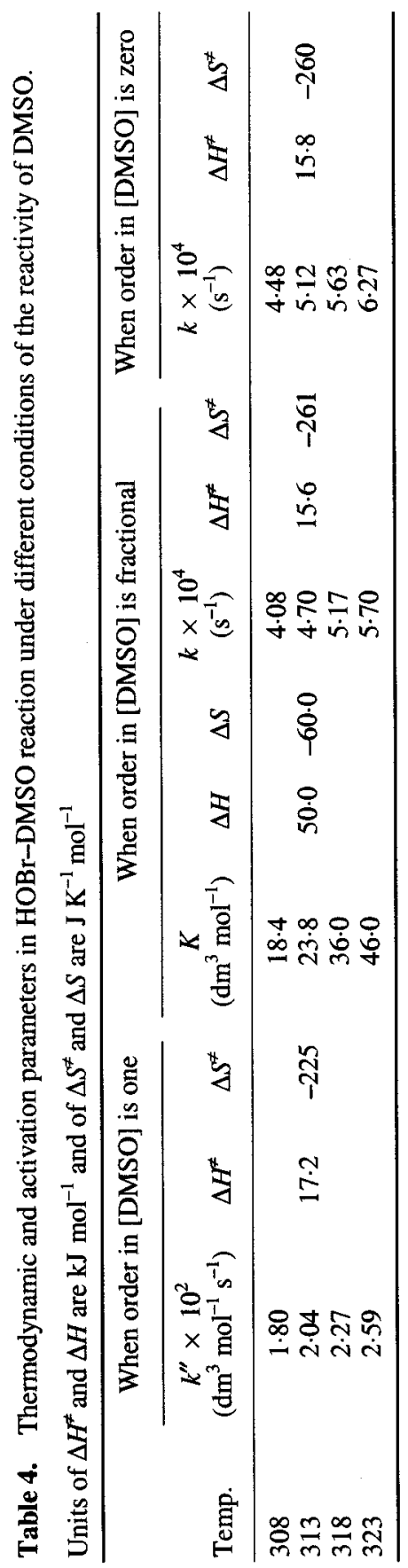


Equation (5) accounts for the first-order dependence of rate on $[\mathrm{HOBr}]$ and fractional order dependence on [DMSO].

Taking the reciprocal of (6) at constant [DMSO],

$$
\frac{1}{k_{\mathrm{obs}}}=\frac{1}{k K[\mathrm{DMSO}]}+\frac{1}{k}
$$

A plot of $1 / k_{\text {obs }}$ versus $1 /[\mathrm{DMSO}$ ] is linear, the slope of which is equal to $1 / k K$ and the intercept equal to $1 / k$. The ratio of intercept to slope gives the value of $K$ and the reciprocal of intercept gives the value of $k$.

At [DMSO] $>0.5 \mathrm{~mol} \mathrm{dm}^{-3}$ a zero order dependence in [DMSO] is observed, which may be explained as follows: When [DMSO $][\mathrm{HOBr}],[1+K[\mathrm{DMSO}]] \approx$ $K[\mathrm{DMSO}$. Hence (5) can be rewritten as

$$
\text { rate }=k[\mathrm{HOBr}],
$$

which explains the zero-order dependence on [DMSO]. At [DMSO] $<0.01 \mathrm{~mol} \mathrm{dm}{ }^{-3}$, a first-order dependence on [DMSO] is observed. When $1+K[\mathrm{DMSO}] \approx 1,(5)$ reduces to,

$$
\text { rate }=k^{\prime \prime}[\mathrm{DMSO}][\mathrm{HOBr}],
$$

where $k^{\prime \prime}=k K$, the second-order rate coefficient. All the results are tabulated in tables $1-3$.

\section{Effect of temperature}

The reaction rates of oxidation of DMSO increase with increase in temperature and the values of $K$ and $k$ also increase with temperature. Thermodynamic parameters for the adduct formation (step 3 ) and the activation parameters for the decomposition of the adduct (step 4) were evaluated from Eyring plots, when order in [DMSO] is fractional. Also the activation parameters were determined for the other two conditions, i.e. when order in [DMSO] is zero and one and are tabulated in table 4. The negative $\Delta S^{\neq}$for all the three conditions is due to the strong solvation of $\mathrm{HBr}$. The negative $\Delta S$ when order in [DMSO] is fractional is due to the formation of an ionic 4-membered cyclic transition state, which may be solvated to a greater extent.

\section{Acknowledgement}

One of the authors (JVP) is grateful to the University Grants Commission, New Delhi, for a fellowship.

\section{References}

1. Mahadevappa D S, Ananda S, Madegowda M B and Rangappa K S 1984 Indian J.Chem. A23 325

2. Mahadevappa D S, Ananda S, Murthy A S A and Rangappa K S 1984 Tetrahedron 401673

3. Mahadevappa D S, Jadhav M B and Naidu H M K 1979 Int. J. Chem. Kinet. 11261

4. Ranga Swamy and Yathirajan H S 1981 Curr Sci 17757 
5. Pandey S M, Sharma J, Prakash O and Mushram S P 1981 Indian J. Chem. A20 1021

6. Radhakrishna Murthy P S and Sahu N C 1981 Indian J. Chem. A20 269

7. Venkateshwarlu S and Jaganmadham V 1985 React. Kinet. Catal. Lett. 27293

8. Sharadamani P R and Jagannadham V 1991 Indian J. Chem. A30 518

9. (a) Ohta H, Motoyama T, Ura T, Ishii Y and Ogawa M 1989 J. Org. Chem. 54 1668; (b) Masuda H, Takase K, Nishio M, Hasegawa A, Nishiyama Y and Ishii Y 1994 J.Org. Chem. 59 5550; (c) Ohta H, Sakata Y, Takeuchi T and Ishii Y 1990 Chem. Lett. 733; (d) Takase K, Masuda H, Kai O, Nishiyama Y, Sakaguchi S and Ishii Y 1995 Chem. Lett. 871.

10. Cotton F A and Wilkinson G W Advances in inorganic chemistry (New Delhi: Wiley Eastern) pp (a) 569, (b) 197. 